\title{
O Direito nas trincheiras da cidade: urbanismo corporativo e práticas contra-hegemônicas
}

The law in the city's trenches: corporate urbanism and counter-hegemonic practices

\section{Adriana Nogueira Vieira Lima'}

1 Universidade Estadual de Feira de Santana, Feira de Santana, Bahia, Brasil. E-mail: adriananvlima@gmail.com. https://orcid.org/0000-0002-3481-7970.

\section{Liana Silvia de Viveiros e Oliveira²}

2 Universidade Católica do Salvador, Salvador, Bahia, Brasil. E-mail: piuviveiros@gmail.com. https://orcid.org/0000-0002-5842-0169.

\section{Maria José Andrade de Souza ${ }^{3}$}

3 Universidade Federal do Sul e Sudeste do Pará, Marabá, Pará, Brasil. E-mail: mariaandrasouza@gmail.com. https://orcid.org/0000-0003-3354-3717

Artigo recebido em 4/02/2020 e aceito em 10/02/2020.

\section{$(\mathrm{cc}) \overline{\mathrm{EY}}$}

This work is licensed under a Creative Commons Attribution 4.0 International License. 


\section{Resumo}

Os conflitos urbanos inscrevem tensões próprias dos seus contextos de ocorrência, capazes de revelar contradições e apontar sentidos das disputas, quando observados como parte da lógica capitalista de produção do espaço. Colocam como desafio à pesquisa acadêmica, adentrar esses processos em uma práxis de alinhamento entre a produção de conhecimento e a ação política, pela chave do direito à cidade. Com o recurso à observação participante, conforme referencial aportado por Burawoy (1998) são discutidos três conflitos, ainda em processo, nomeados aqui como Centro de Abastecimento de Feira de Santana, Horto Bela Vista e Elephant and Castle, inseridos, respectivamente, em Feira de Santana - BA, Salvador - BA e Londres, desencadeados a partir de projetos urbanos. Em operação analítica, o artigo problematiza os conflitos em seus contextos, na busca de refletir sobre os recursos jurídicos aportados, formas de juridicidades produzidas e sentido das lutas pelo direito à cidade, valendo-se de um referencial teórico trazido da ciência política, dos estudos culturais e da teoria crítica do Direito. Em sintonia com as perspectivas teóricas e metodológicas adotadas, acena para a compreensão dos processos conflitivos contemporâneos em cidades distintas em complexidade e escala e afirma sentidos convergentes das lutas de sujeitos coletivos de direitos pelo direito à cidade.

Palavras-chave: Direito à Cidade; Direito Urbanístico; Conflito.

\section{Abstract}

Urban conflicts inscribe tensions specific of their contexts of occurrences capable of revealing contradictions and pointing out meanings of disputes, when observed as part of the logic of capitalist production of the space. Entering these processes in a praxis of alignment between the production of knowledge and political action, under the key of the right to the city is a challenge to academic research. Using participant observation, according to the framework provided by Burawoy (1998), three conflicts, triggered by still in process urban projects, are discussed. They are named here as the Centro de Abastecimento de Feira de Santana (Supply Center of Feira de Santana), HortoBela Vista, and Elephant and Castle, located, respectively, in Feira de Santana and Salvador in Bahia, Brazil and London, in the UK. Through an analytical operation, this paper problematizes these conflicts in their contexts, searching to reflect on the legal resources, forms of 
produced legalities and the senses of the struggles for the right to the city, drawing on a theoretical framework from political science, cultural studies and the critical theory of law. In line with the adopted theoretical and methodological perspectives, we hint at understanding contemporary conflicting processes in different cities in their complexity and scale and affirm converging meanings of the struggles of collective subjects of rights for the right to the city.

Keywords: Right to the City; Urban Law; Conflict. 


\section{Introdução}

Refletir sobre a questão urbana através da chave do direito à cidade é um desafio que ultrapassa as fronteiras acadêmicas e nos leva a navegar pelo mar revolto dos fatos sociais e da práxis jurídica. Impõe, como propõe Henri Lefebvre (1991), adotar uma estratégia de conhecimento de forma inseparável de uma estratégia política, e construída em direção à prática de um direito (LEFEBVRE, 1991), que ultrapasse a sua concepção positivista para alcançar as múltiplas expressões de juridicidade que emergem dos territórios populares. A partir dessas premissas são revisitados os fundamentos do direito à cidade, nos termos lefebvrianos, de modo a conceber a cidade na sua perspectiva transformadora.

Com o olhar lançado para três conflitos envolvendo o direito à cidade - dois no Brasil e um no Reino Unido e sem a pretensão de estabelecer comparações diretas entres eles, buscamos encontrar pontos de intersecção entre o direito e o urbanismo, em perspectivas entrecruzadas, no sentido de: a) investigar como o corpus jurídico do Direito Urbanístico, com seus instrumentos, conceitos e interpretações é disputado pelo urbanismo corporativo e pelos sujeitos coletivos de direito; b) discutir como as múltiplas formas de juridicidade (positivadas ou não) são acionadas pelos habitantes nas reivindicações do direito à cidade e c) refletir sobre os sentidos da luta pelo direito à cidade a partir dessas tensões em torno dos usos de territórios populares, frente à interesses empresariais. Resguardadas as suas particularidades, os conflitos trazem como processos comuns o avanço do capital sobre territórios conquistados, a tentativa de estigmatização dos territórios para legitimar ações arbitrárias e, em destaque, o acionamento de instrumentos jurídicos protetivos de direitos e o manejo das ambiguidades dos estatutos jurídicos, construídos na forma jurídica-propriedade.

Longe de modelos idealizadores apoiados na separação entre cidade real e cidade legal, a análise proposta lança o olhar sobre os "sujeitos coletivos de direito" em ação e como enfrentam no cotidiano as investidas do capital sobre seus territórios. Por essa opção metodológica e valendo-se do conceitos de hegemonia em Gramsci (2012) e sua potente problematização no campo da cultura trazida por Williams (2004), de experiência em Thompson (1981) e em diálogo aproximado com o campo do direito

${ }^{1}$ Categoria utilizada por José Geraldo de Sousa Junior (2011) para definir os sujeitos capazes de estruturar um projeto político de transformação social e criação de novos direitos. 
crítico (LYRA FILHO, 1980, dentre outros), discute-se o direito à cidade (LEFEBVRE,1991) no terreno poroso das lutas por direitos protagonizadas pelos grupos populares, de modo a apreendê-lo enquanto categoria em movimento, dimensão criativa e insubordinada dos agentes que produzem a cidade e dela se apropriam no processo conflitivo dessa produção.

Na observação e análise dos conflitos procuramos ir além da sua compreensão como fato ou fenômeno da realidade social na tentativa de captar os processos ativos nas relações entre os agentes implicados e assim identificar os sentidos das lutas e seu potencial de ir além dos limites do próprio conflito. Como orienta Lyra (1984, p.8), "a correnteza dos fatos sociais - isto é, a práxis jurídica inteira e sem mutilações - forma a energia esclarecedora das ideias, que logo regressa às mesmas águas potentes, estabelecendo a conexão com o fluxo da realidade móvel, sem a qual não há luz, nem se faz avançar o saber". Essa práxis jurídica insere-se em processos sociais e políticos complexos e articula-se à produção de conhecimento como descoberta de significados e direções comuns na formação da sociedade urbana, ou seja, como processo cultural de produção da cidade. Como destaca Williams $(2015$, p. 5) a cultura representa "todo um modo de vida"; é processo social ativo e criativo constantemente produzido, vivido e transformado, e assim é a cidade, produzida, transformada e recriada na disputa de hegemonia por visões de mundo e projetos de sociedade.

Os casos estudados, aqui referenciados como Centro de Abastecimento de Feira de Santana, Horto Bela Vista e Shopping Center E\&C (Elephant and Castle),estão inseridos, respectivamente, em Feira de Santana - BA, Salvador - BA e Londres, contextos distintos de conflitos territoriais desencadeados por projetos urbanos e seus processos específicos de inserção nas cidades, que não passam ilesos às reações contestatórias, expressões das disputas entre projetos e concepções distintas de sociedade e de cidade. Em condições assimétricas de recursos de poder, os sujeitos coletivos de direitos constroem estratégias e acionam táticas dentro e fora da ordem dominante e na posição de agentes interessados no conflito tensionam perspectivas de interação em trincheiras nas quais as contradições afloram. Em sentido contrário, ficam evidentes as movimentações dos agentes públicos no sentido de deslocamento do conflito para arenas cujos repertórios, recursos de poder e instrumentos (inclusive a lei) são controlados. Nessas arenas, onde as cadenas para a 
eliminação do conflito são manejadas nas esferas técnica e jurídica para o banimento da política, o exercício da "utopia da cidade negocial" (VAINER, 2007, p.5) ganha expressão.

Para discutir esses processos, acionamos o extended case method nos termos propostos por Burawoy (1998) na busca de uma aproximação sensível e reflexiva. Por essa opção metodológica, o autor propõe uma interação com os sujeitos do conhecimento, afastando-se do distanciamento epistemológico proposto pelo positivismo. Esse engajamento, por sua vez, possibilita, ainda segundo o autor, ir a fundo nos binômios políticos e suas contradições. No nosso caso, o olhar para as dicotomias hierarquizantes repercutiu em duas novas escolhas. A primeira nos levou a investigar a ação estatal manifestada por meio das normas jurídicas e das políticas urbanas, a partir das suas margens, consideradas por Das e Poole (2004), como locais onde a lei e outras práticas estatais estão permeadas por formas de regulação que emanam das necessidades prementes das populações para garantir a sobrevivência política e econômica. A segunda escolha, ensejou uma postura militante, pautada no entrelaçamento entre fazer e o pensar, e na compreensão da teoria como "consciência cartográfica do caminho que vai sendo percorrido pelas lutas políticas, sociais e culturais que ela influencia tanto quanto é influenciado por elas" (SOUSA SANTOS, 2000, p.37).

Essas ideias fundamentam uma opção de análise dos conflitos não adstrita à ação pura e simples dos grupos de poder e de sua capacidade de constranger e mobilizar instrumentos e instâncias a seu favor. Deslocar os casos para as trincheiras do direito à cidade significa ultrapassar as evidências de certos resultados imediatos - as conquistas, as derrotas etc. - e assim, como diria Thompson (1998), evitar "os atalhos da história" como condição para alcançar a "agência humana"2 (THOMPSON, 1981) no fazer e destecer do processo histórico nas disputas de hegemonia. Como proposto por Williams (2004, p.116), importa identificar e discutir "formas de política e de cultura alternativas" e explorar suas condições e seus limites, nos percursos pelas margens e brechas na ordem dominante.

A pesquisa contou com ampla revisão bibliográfica, consulta a estudos, planos, projetos, legislação e decisões judiciais, mas se valeu, sobretudo, da interlocução com as lideranças de Saramandaia e Pernambués (Salvador) e acompanhamento em audiências

${ }^{2} \mathrm{~A}$ concepção de "agência humana" é central no pensamento de Thompson e de outros historiadores marxistas ingleses, que refutaram o marxismo estruturalista dada a sua incapacidade de reconhecer a ação transformadora dos sujeitos sociais no processo histórico. 
públicas e nos órgãos judiciais, de 2013 até o presente momento; da interlocução com as lideranças do Centro de Abastecimento (Feira de Santana) e acompanhamento do conflito de 2017 até o presente momento e da interlocução estabelecida com os comerciantes do Shopping Center E\&C (Elephant and Castle - Londres) e ativistas do 35\% Companig e Just Space, durante o mês de setembro de $2018^{3}$ e acompanhamento dos processos à distância, até o presente. Os modos pelos quais se deram as aproximações aos processos estudados e as condições para o efetivo acompanhamento se diferenciam, ou seja, ofereceram acessos e possibilidades de interações distintas, com implicações na análise proposta, especialmente nas reflexões sobre os sentidos das disputas pelo direito à cidade.

\section{Direito à cidade, conflito e potência do emergente}

Nos processos de disputa pelo direito à cidade, os conflitos urbanos apontam caminho promissor para a reflexão sobre o hegemônico "em seus processos ativos e formativos, e também transformacional" (WILLIAMS, 2004, p.117), nas relações de força em ação. Nesse sentido, possibilita identificar as tensões, os recursos de poder mobilizados e perscrutar os sentidos das lutas pelo direito à cidade, como disputa de hegemonia por uma sociedade urbana e uma cidade alternativas. Em constante instabilidade e sujeita às tensões internas e externas, uma hegemonia é sempre um processo vivido (WILLIAMS, 2004). Como destaca o autor, é um "complexo realizado de experiências, relações e atividades, com pressões e limites específicos e mutáveis" e "não existe apenas passivamente como forma de dominação"; é constantemente renovada e recriada; “desafiada por pressões que não são as suas próprias pressões" (WILLIAMS, 2004, p. 115).

Em todos os casos analisados, o direito à cidade é reivindicado a partir da eclosão do conflito, motivado pela subtração de meios de reprodução da vida na cidade. Portanto, não fogem à regra de inúmeros conflitos gerados nos marcos de condições assimétricas de acesso à cidadania e à cidade, mas diferem pelo fato de estarem em jogo direitos conquistados, ainda frágeis no plano jurídico, mas legitimados pela prática e usos

${ }^{3} \mathrm{O}$ acompanhamento do conflito foi possibilitado pelo intercâmbio acadêmico entre o Grupo de Pesquisa Lugar Comum (UFBA) e MSc Social Development Practice, The Bartlett Development Planning Unit. 
costumeiros. Essa particularidade pauta a natureza do conflito com a possibilidade de tensionar para além das resistências de garantia da situação presente ameaçada, construir repertórios e ampliar os horizontes de reivindicação e conquista.

O conflito revela dimensões e modos de disputa, além de assumir diversas configurações e expressões no tempo, em seu contexto. Em momentos de maior evidenciação dos antagonismos de posições, as relações entre os agentes podem tanto mostrar, como ocultar as entranhas dos embates de valores, crenças, projetos e visões de mundo. Nos casos observados, o conflito não se coloca como impasse entre opositores, dado que os agentes em disputa não se desprezam mutuamente e apostam na resolução do conflito na perspectiva de fortalecimento das suas posições ou alcance dos seus objetivos. Embora, por óbvio, não seja possível generalizar, é plausível a hipótese de que o conflito, em princípio, ao contrário de se colocar como interdição agonística (MOUFFE, 2007) ou como uma crise agonística, entendida como impossibilidade de reconhecimento da legitimidade do outro, o conflito quando estabelecido, revela condições de importância das partes envolvidas e altera posições e relações de poder.

No conflito, em regra, os papéis e as relações de força se alteram diante das condições objetivas e subjetivas no transcurso da ação política. O conflito, portanto, tem seus momentos e pode se apresentar na condição de evento ou nas tensões cotidianas de disputa. Nas duas formas de existência e experiência pode evidenciar o emergente ou desembocar em conciliação na esfera do dominante. Embora a potência do conflito seja crucial na transformação das condições do seu desenvolvimento, nem sempre inscreve potencial de sinalizar o emergente. É preciso questionar, portanto, qual o sentido da transformação pois, conforme destaca Williams (2004), o emergente se apresenta em processo e em potencial nos processos culturais e deve ser distinguido das novas formas do dominante.

Ao perscrutar possíveis sinais do emergente, importa observar nas situações conflitivas os processos culturais de incorporação (WILLIAMS, 2004), importante nas disputas de hegemonia enquanto construção de sentido da direção moral e intelectual da sociedade (GRAMSCI, 2012). Como destaca Gomes (2011), reportando-se a Williams, é a relação entre valores e sentidos dominantes e valores e sentidos alternativos que permite "compreender o processo contínuo de renovação, recriação, tensionamento, conflito, resistência que caracteriza a hegemonia e que nos possibilita pensar que, ao menos em 
tese, uma hegemonia pode ser modificada". Como processo social e cultural, o conflito pode ensejar tensões de mudança em sua dinâmica política e em sua potência fazer aflorar valores, sentidos e práticas alternativas e oposicionais que podem ser acomodados à cultura dominante, sem fazer parte dessa cultura, podem ser deixados de lado ou não ser tolerados, dependendo "de quão alerta a cultura dominante é e em que áreas da vida social ela é mais ciosa" (GOMES, 2011, p.41).

Situações de conflito podem ser especialmente relevantes por tensionar processos de mudança cultural na ação política. No embate das forças atuantes, os recursos de poder acionados são diversos e situados na esfera do político, mas são constantemente tensionados no sentido de situá-lo nas esferas técnica e jurídica. Esse deslocamento para as arenas reguladas, codificadas e controladas inscreve o conflito na dimensão do que Mouffe (2007) define como política - um conjunto de práticas e instituições por meio das quais se cria uma determinada ordem no contexto conflitivo da esfera do político, quando passa a operar a "política dos técnicos" (NOGUEIRA, 2001) para diluir ou aniquilar o político.

É na esfera das relações de produção e de reprodução social e na produção da cidade como obra, sempre imbricados no processo cultural, que as contradições desses processos emergem e o político ganha evidência como "antagonismo constitutivo das sociedades humanas" (MOUFFE, 2007). Nessa perspectiva, o conflito se apresenta como momento de construção de identidades, projetos e práticas coletivas e de alinhamento na ação política:

[...]é a luta social, o conflito aberto o principal, senão o único, caminho através do qual grupos sociais dominados constituem-se enquanto sujeitos coletivos no espaço público - isto é, enquanto sujeitos políticos. Sem conflito, não podem os grupos e classes sociais dominados gerarem identidades, projetos coletivos, práticas coletivas, AÇÃO POLÍTICA. (VAINER, 2007, p. 6).

O conflito, assim, é inerente ao processo de formação de consciência crítica na disputa de hegemonia por projetos de sociedade e de cidade. $\mathrm{O}$ direito à cidade, como projeto político, assume, nos diferentes momentos dos processos sociais conflitivos, diversas acepções, no jogo de forças entre os agentes, conforme agendas em disputa, mais ou menos assimiladas na esfera do dominante, e também das arenas onde se expressam, mais ou menos conhecidas, reguladas e codificadas (VIVEIROS, 2018). Nas 
tensões, o emergente pode se revelar como processo cultural ativo ainda não plenamente compreendido.

Essa premissa do conflito como potência da emergente demanda a problematização da situação conflitiva na sua própria complexidade - agentes envolvidos, agendas, dimensões de disputa, relações de poder e outros aspectos - e o movimento de reflexão sobre o que aporta no sentido da transformação das condições dadas no contexto e nas relações desencadeadoras do conflito. Conquistas, pactuações e acomodações nas relações de força empreendidas e do reposicionamento dos agentes no próprio conflito com o acionamento de recursos de poder, inclusive do campo jurídico, revelam mudanças na configuração do território nas dimensões material e simbólica, mas é preciso ir além no exame das disputas em torno da situação em si, na tentativa de entender os sentidos da luta pelo direito à cidade. Como aponta Viveiros (2018) a disputa pelo direito ao centro e à centralidade, o empenho pela legitimação pública dos seus direitos e a reivindicação da dimensão do espaço público e comum da cidade, no período recente, estão no âmago das estratégias de resistência e disputa pelo direito à cidade, mesmo no Brasil e outros países da América Latina, onde as condições básicas de reprodução social não estão dadas à grande parte dos habitantes urbanos.

Em outra perspectiva, Lima (2019) assinala o potencial das situações conflitivas no aporte de repertórios para o alargamento de uma pluralidade de juridicidades. Adentra na esfera de construção de direitos, ou "direitos autoconstruídos" na acepção da autora, e do acionamento de camadas entrelaçadas de juridicidade nem sempre reconhecidas e aplicadas pelo judiciário. Nessas ocasiões, a institucionalidade é convocada para adoção de novos repertórios, construção de jurisprudências e mesmo para evocar direitos não atendidos e não reconhecidos. Esse mesmo campo, capaz de ampliar o horizonte de possibilidades de recursos de poder dos sujeitos sociais ameaçados nos seus direitos é também o que regula e estabelece pressões e limites para a manutenção das soluções dos conflitos nas fronteiras do dominante. Esse também é um campo de imensas contradições e tensões próprias da disputa de hegemonia e onde principalmente se embaralham os sentidos e opera-se o que Dagnino (2004) chama de "confluência perversa" entre projetos políticos antagônicos. Comparecem nessa operação representações de cidade, alargando e confundindo os repertórios e instrumentos de disputa (VIVEIROS, 2018). 
3 Mobilizando as trincheiras pelo direito à cidade

Mobilizar o direito à cidade por meio de suas trincheiras significa assumir uma postura teórica e metodológica que enfatiza o lugar do conflito e as formas pelas quais assume nas arenas jurídicas e políticas. Sem perder de vista a desigual correlação de forças entre os grupos e seus propósitos, assumimos o desafio de refletir a partir do direito à cidade, considerando a maneira como os sujeitos coletivos de direito, mediados pela experiência ${ }^{4}$ (THOMPSON, 1981) e sob condições históricas e sociais datadas, reagem aos projetos que alteram suas próprias vidas e, com isso, resistem com "necessidades" e "expectativas", reatualizando, permanentemente, o lugar e o sentido das lutas por direitos. Se essa reação obstinada de grupos e comunidades que resistem em face de constrangimentos físicos e legais - ora acionando as estruturas jurídicas estatais, ora afirmando noções costumeiras de direito (THOMPSON, 1998) - não é capaz de reverter os processos de segregação em curso, não se pode afirmar que não possam fornecer elementos para reflexão sobre o lugar e o potencial das insurgências populares nas disputas pelo direito à cidade, que são também “disputas de sentido sobre a história” (HOLSTON, 1993).

Dito deste modo, sem negar a história particular de cada conflito, seus repertórios e suas condições objetivas e subjetivas, nesse conjunto heterogêneo de agentes e suas variações de contextos, são evidenciados pontos convergentes que podem ser indicativos de expressões contemporâneas que marcam as lutas pelo direito à cidade. Ainda que seja possível assinalar uma crise do discurso higienista, tão utilizado nas décadas anteriores, o seu conteúdo é lapidado e reapresentado em novas roupagens materializadas em projetos urbanos, nos seus diferentes modelos - revitalização, requalificação, regeneração, renovação e outros -,em regra produtores de gentrificação,

\footnotetext{
${ }^{4}$ Experiência é uma categoria acionada por Thompson (1981), no esforço de aprofundar a concepção marxista sobre a relação entre o ser social e a consciência social, considerando as distintas experiências pelas quais as classes se fazem e nessa condição se reconhecem enquanto tal. Nesse sentido, contrapõe-se à "prática teórica" althusseriana para recordar que as classes não são anteriores às suas lutas (THOMPSON, 1981, p. 179-183). Por essa concepção, a análise sobre as lutas protagonizadas pelos grupos e comunidades relacionados aos conflitos aqui referenciados perpassa pelo reconhecimento das suas relações étnicas e raciais, relações cidade-campo, migrações e específicos arranjos e condições socioeconômicas de reprodução da vida.
} 
e enseja variadas formas de resistência e ação política, como poderá ser visto nos casos em análise.

3.1 Centro de Abastecimento de Feira de Santana (CAF): expressões culturais e resistências frente à demolição e à mercadorização dos usos populares

O conflito em torno do Centro de Abastecimento de Feira de Santana (CAF) está inserido no contexto do projeto denominado Pacto pela Requalificação do Centro Comercial de Feira de Santana. A intervenção urbana envolve a demolição de parte das instalações do CAF, que era destinada à confecção e comercialização de artesanato, para dar lugar à construção do Centro de Comércio Popular (CCP) de Feira de Santana.

A construção do CCP teve início em outubro de 2017 com a remoção de um grupo de artesãos para uma área mais afastada do centro comercial da cidade, ocasionando diversos prejuízos materiais e imateriais - e não somente aos diretamente impactados -, tendo em vista a importância socioeconômica, política e cultural do CAF e seus vínculos constitutivos com a formação histórica e a configuração socioespacial de Feira de Santana, que se revela, dentre outros, por suas interações entre o urbano e o rural e com o comércio, que inscreve a feira tradicional no seu próprio nome.

Considerado o maior entreposto comercial do interior do Nordeste, no Centro de Abastecimento de Feira de Santana ocorrem, diariamente, múltiplas e significativas interações de caráter comercial e cultural. Além da área demolida, que compreendia o setor de artesanatos, o CAF ainda abrange uma área destinada à comercialização de gêneros alimentícios, oriundos de diversas regiões e da zona rural de Feira de Santana. Por essa função, conta com a presença majoritária das classes populares - suas práticas e usos costumeiros, que marcam e dão contorno às experiências coletivas compartilhadas em rotinas diárias de trabalho naquele espaço. Como expressão ritualística dessas interações materiais e simbólicas, todos os anos, mais de três mil fiéis se deslocam da Igreja Senhor dos Passos em direção ao CAF para os festejos comemorativos de Santa Bárbara, que é símbolo do sincretismo religioso e de devoção à padroeira de comerciantes e feirantes daquele local.

Por essa importância socioeconômica e cultural e tendo em vista a sua associação com as feiras tradicionais do município, a Associação de Artesãos de Feira de 
Santana requereu ao Estado da Bahia a patrimonialização do CAF (GOMES, 2018) como forma de impedir os possíveis danos decorrentes das obras do CCP. A partir deste pleito, as práticas comerciais e culturais tradicionais efetuadas naquele espaço foram reconhecidas, em julho de 2017, através do Registro Especial, como bem cultural imaterial estadual pelo Instituto do Patrimônio Artístico e Cultural (IPAC), autarquia estadual vinculada à Secretaria de Cultura do Estado da Bahia. Em vista disso, no processo de remoção dos artesãos, o IPAC determinou a paralisação da demolição do prédio de onde emergem as manifestações culturais merecedoras de proteção, mas o poder público municipal desconsiderou o termo de embargo extra judicial e prosseguiu com a obra do CCP, denominado "Cidade das Compras".

O empreendimento vem sendo construído através do regime de Parceria Público-Privada, numa área de $30.000,00 \mathrm{~m}^{2}$, no Centro de Feira de Santana, pela Concessionária Feira Popular - uma Sociedade de Propósito Específico constituída pela Rede UAI Shopping, que é gestora de empreendimentos similares em outras cidades brasileiras. A empresa, vencedora da licitação $0^{5}$, tornou-se responsável pela construção, operação, manutenção e exploração econômica do empreendimento pelo prazo de 30 anos, com possibilidade de prorrogação, nos termos da concessão comum subsidiada, celebrada com o Poder Público Municipal, que arcou com um subsídio inicial de R\$ 13.000.000,00 (treze milhões de reais).

A demolição de parte do CAF para construção do CPP ultrapassa a retirada forçada dos artesãos quando o projeto prevê, simultanemente, a remoção de ambulantes e camelôs das ruas para serem relocados no empreendimento Cidade das Compras, mesmo sem dispor de estrutura compatível para absorver o quantitativo de trabalhadores do comércio informal, localizado nas principais ruas e avenidas do Centro da cidade, que, segundo estimativas, é em torno de cinco mil. ${ }^{6}$

Ademais, nos documentos que informam sobre o empreendimento não há menção a garantias para os vendedores ambulantes e camelôs quanto às condições de acesso e permanência no CCP com os aluguéis de boxes, que podem, inclusive, ser explorados por outros comerciantes. Como agravante, o contrato firmado com a empresa concessionária obriga o Poder Público Municipal a impedir o comércio informal por meio

5Licitação no 108/2015, na modalidade Concorrência Pública no 014/2015.

'São resultados do Censo "Contagem Parcial de Camelôs e Ambulantes do Centro Comercial de Feira de Santana/BA" sob a coordenação da Profa. Dra. Alessandra Oliveira Teles. 
do exercício do seu poder de polícia. Ou seja, independentemente da viabilidade econômica do empreendimento, camelôs e ambulantes estarão impedidos de permanecerem nas ruas.

Nesse sentido, de "paraíso de compras populares", o CCP vem sendo encarado como uma "tragédia anunciada" - expressão utilizada pelas lideranças do movimento de camelôs e ambulantes. Diante das incertezas sobre as garantias do seu meio de sobrevivência, essas lideranças, que são majoritariamente mulheres de diversos ramos do comércio informal de Feira de Santana- artesanato, confecção de roupas, calçados etc. vêm reagindo a este projeto por meio de manifestações de ruas, audiências públicas e a partir da incidência institucional junto ao poder público municipal e aos órgãos do sistema de justiça.

Para dar maior visibilidade às suas reivindicações, o referido grupo de lideranças - que não constitui exatamente um movimento social, nem mesmo se vincula a entidades de classe ou partidárias - conta com a colaboração de docentes e estudantes das instituições de ensino superior local, que se dedicam a traduzir em termos técnicos e jurídicos os possíveis danos socioeconômicos e culturais - materiais e imateriais -e as violações de direitos decorrentes da construção do CCP. Outrossim, na medida em que vão sendo publicizadas as informações a respeito das cláusulas contratuais para exploração do CPP, as mobilizações, que foram iniciadas pelo grupo de artesãos removidos do CAF, vão catalisando um número mais abrangente e diversificado de trabalhadores do comércio informal, inclusive, com reflexos na sociedade feirense nas disputas em torno da legitimidade e do caráter público de suas pautas quando se contrapõem aos argumentos da legalidade, da cidadania e ordenação das ruas e do comércio, que são acionados pelo poder público para justificar a requalificação do centro comercial da cidade por meio da remoção de camelôs e ambulantes.

Além de apontar as cláusulas contratuais da minuta do contrato de concessão, que consideram abusivas, o movimento de ambulantes e camelôs denuncia a ausência de diálogo com o poder público e a omissão de informações públicas relevantes sobre o empreendimento; possíveis danos ao meio ambiente; descumprimento da legislação trabalhista quanto aos trabalhadores da construção civil e a demolição do setor de artesanatos do CAF, além da subtração dos meios de reprodução da vida na cidade. Ou seja, constroem uma agenda para além das suas demandas específicas enquanto grupo 
social afetado pelo empreendimento. A ampliação dessa agenda de lutas para alcançar outras situações de ilegalidade é acompanhada do deslocamento de suas demandas para os espaços institucionais de decisão. Assim, mobilizam por dentro das arenas jurídicas a atuação de órgãos do sistema de justiça - Ministério Público, Defensoria Pública - com alguma capacidade de confrontar a atuação empresarial e do poder público municipal na esfera da legalidade, com as inerentes ambiguidades e contradições.

Em vista disso, o caso do CAF, no plano das intervenções urbanas, se insere no terreno de confrontações entre distintos projetos de cidade, que passam tanto pelas ações institucionais e suas investidas para remoção de camelôs e ambulantes das ruas, quanto pelas resistências inscritas em certos usos populares do espaço urbano, com seus arranjos específicos no contexto do trabalho informal, suas relações étnicas e raciais. Reflexões abertas pela pesquisa de Pacheco (2009) oferecem algumas pistas para associarmos o atual Pacto pela Requalificação do Centro Comercial de Feira ao projeto autoritário de produção de cidade, que, historicamente, se materializa na forma de planos de governo, de ações institucionais e repressoras, promovidas pelo poder público local e mesmo pelas reivindicações segregadoras de grupos políticos locais e entidades de classe.

No atual contexto, as intervenções urbanas sobre o CAF, assim como se deu com o deslocamento de feirantes da Feira Livre para o Centro de Abastecimento, em 1977, também podem ser analisadas numa "conjuntura de construção de códigos de regulamentação que culminam na retirada oficial de trabalhadores informais do centro da cidade" (PACHECO, 2009, p. 16), com as investidas para destruição autoritária das tradições populares, a remoção das classes populares e de suas práticas costumeiras nos espaços centrais da cidade, no caso específico, os camelôs e ambulantes.

Por outro lado, esse projeto autoritário de cidade não se impõe sem resistências e embates. Não é demais destacar, como acentua Henri Lefebvre (1999), que a rua é o lugar privilegiado do movimento e da desordem que vive, informa, surpreende e engendra uma outra ordem, uma vez que "na rua, e por esse espaço, um grupo (a própria cidade) se manifesta, aparece, apropria-se dos lugares, realiza um tempo-espaço apropriado" (LEFEBVRE, 1999, p. 29). Nessa direção, enquanto se contrapõem à edificação do empreendimento Cidade das Compras, as lideranças do movimento de camelôs e ambulantes afirmam o sentido e a centralidade do comércio informal na produção de uma cidade que tem a sua constituição histórica associada ao comércio popular e de rua - 
espaço onde se diluem as fronteiras tênues entre o legal/ilegal, formal/informal (TELES, 2017). Dessa maneira, o que vem sendo concebido pelo chamado Plano de Requalificação Urbana como presença indesejada na cidade, se insurge para permanecer no Centro, reatualizando e contextualizando a luta pelo direito à cidade, que, no presente caso, coincide com a resistência teimosa de camelôs e ambulantes frente à engenharia política e jurídica, que insiste em convertê-los à condição de estranhos no espaço público e comum da cidade.

Nesse sentido, o conflito aqui referenciado ultrapassa os limites físicos do CAF na medida em que expõe e reatualiza enfrentamentos físicos e simbólicos oriundos de concepções distintas de direitos de uso e ocupação do Centro de uma cidade que lida de uma maneira um tanto quanto paradoxal com suas próprias origens, associada à feira de rua e ao comércio popular. Por esse olhar, enquanto as ações institucionais se direcionam no sentido da mercadorização do comércio popular sob a negação ou mesmo fetichização das classes populares, o movimento de camelôs e ambulantes mobiliza as trincheiras do direito à cidade e com isso reativa, no tempo presente, o sentido e os rumos da história de produção de uma cidade pelo seu centro e na condição de sujeitos.

3.2 Horto Bela Vista (HBV): projeto urbano, resistências e afirmação de legitimidade de um território popular em Salvador

O conflito Horto Bela Vista (HBV) decorre da implementação de um megaempreendimento homônimo, em área situada na vizinhança de duas comunidades, cujos territórios encontram-se demarcados como Zonas Especiais de Interesse Social (ZEIS). Para situar o conflito é preciso retomar o contexto de criação das condições para o empreendimento se concretizar, quando da elaboração do Plano Diretor de Desenvolvimento Urbano do município do Salvador, aprovado em 2004. Uma grande área com remanescentes de Mata Atlântica, situada no bairro do Cabula, era mantida como reserva de valor e, na ocasião, duas decisões foram tomadas no planejamento da cidade para valorização da área: a criação de uma nova centralidade, o Centro Retiro-Acesso Norte e o aumento do potencial construtivo da área. Em 2005, com o PDDU/2004 aprovado, o projeto do HBV inicia o seu conturbado e conflituoso processo de implantação. 
O projeto foi concebido como uma urbanização integrada com edifícios residenciais, um shopping center, uma escola, edifício de escritórios e um clube privados, em 330 mil metros quadrados de área, por iniciativa da JHSF Salvador Empreendimentos e Incorporações S/A, associada a uma empresa local do ramo de shopping centers, a Euluz Empreendimentos Imobiliários. O empreendimento tem seu espaço delimitado por muros que demarcam as suas fronteiras, tanto com o bairro do Cabula, onde está inserido, quanto com as ZEIS de Pernambués e Saramandaia, localizadas na vizinhança. Foi o primeiro de Salvador com esse arranjo de usos diversificados e de grande porte, e vem sendo executado conforme estratégia do negócio. Inicialmente foi implantado o shopping center, inaugurado em 2012, depois três empreendimentos residenciais com nove torres, concluídos em 2017, e posteriormente a escola de ensino fundamental. Os demais componentes do empreendimento, inclusive prédios de comércio e serviços, ainda não foram implantados.

O empreendimento é representativo dos processos de incursão avassaladora do urbanismo corporativo nas cidades, tanto pela complexidade e impactos gerados, quanto pelo que logrou mobilizar de forças sociais com o conflito. Uma das comunidades mais afetadas foi Saramandaia, com cerca de 12.000 habitantes em 2010 (IBGE, 2010), localizada na principal centralidade da cidade, a região do Iguatemi, nos limites com a nova centralidade criada. Saramandaia foi uma das inúmeras ocupações de terras ocorridas nos anos 1970, na cidade do Salvador, e tem conseguido resistir a diversos processos de remoção (LIMA, 2019). Parte da área que veio a ser ocupada pelo empreendimento era utilizada pela comunidade para o lazer, coleta de frutas, plantações e rituais sagrados do povo de santo.

Os impactos do megaprojeto imobiliário e as ameaças subjacentes mobilizaram a população no sentido de conhecer as interferências e assim buscar mecanismos de mitigação ou compensação. No processo, foi acionado o Ministério Público, que instaurou inquérito civil para apurar os possíveis danos socioambientais no território. Foi então encaminhado processo de ajustamento de conduta, constatadas a ausência de Estudo de Impacto de Vizinhança e Estudo de Impacto Ambiental (EIA/ RIMA) na aprovação do empreendimento. No curso do processo, a comunidade de Saramandaia passou a contar com a assessoria técnica do Grupo de Pesquisa Lugar Comum, da Universidade Federal da 
Bahia que, dentre outras ações desenvolvidas com a comunidade, estava engajado na elaboração do Plano de Bairro.

Entre processos contenciosos e arranjos de negociação foi firmado Termo de Ajustamento de Conduta, instrumento extrajudicial celebrado para compor conflitos que envolvam direitos coletivos, entre o empreendedor e o Ministério Público da Bahia, que estabeleceu medidas de mitigação e compensação de impactos previstas no Estudo de Impacto Urbano Ambiental (EIUA) com escopo definido para suprir a ausência do EIA/ RIMA e do EIV. O processo aberto pelo Ministério Público, longo, tenso e cheio de idas e vindas, foi um elemento agregador de forças políticas e de aprendizado para as partes envolvidas no conflito, ao colocar em interação, agentes e pautas diversas e possibilitar a ampliação da escala para além da relação do empreendimento com o entorno imediato.

Dentre as comunidades diretamente atingidas, Saramandaia conquistou, na ação política, compensações mais substantivas, dentre as quais uma praça em área de $5.000 \mathrm{~m}^{2}$ e algumas melhorias de infraestrutura. O processo também fortaleceu as lideranças de Saramandaia, que, no processo, conseguiram comprometer a Prefeitura Municipal com a execução de obras de macrodrenagem. Esse acúmulo de força política se revela ainda na formação da Rede de Associações de Saramandaia (RAS), fruto da articulação de diversas associações do bairro. Com efeito, o enfrentamento do contencioso, mesmo em uma arena institucional e regulada, onde o conflito veio a se situar, se desenrolou e foi "pacificado", possibilitou à comunidade de Saramandaia ampliar a escala do conflito, os repertórios e a sua rede de articulação política interna e com outros movimentos, entidades e instituições.

Outros agentes afetados diretamente, como a comunidade de Pernambués, ou engajados no processo, a exemplo do movimento ambientalista Gambá, também lograram compensações, respectivamente, a reforma de uma praça e melhorias urbanísticas e o custeio do projeto de um Observatório Ambiental. Entretanto, toda a articulação política e os recursos jurídicos acionados não foram suficientes para mitigar a fragmentação produzida na cidade e os impactos na mobilidade causados pelo empreendimento. As medidas relativas à mobilidade foram parcialmente implantadas e aquelas voltadas a atenuar e compensar a segregação física, funcional e social imposta pela concepção urbanística segregacionista do empreendimento e a mitigar possível esvaziamento das atividades econômicas pré-existentes, em decorrência do shopping 
center, se diluíram no processo em recomendações sem conexões evidentes com os impactos identificados. O processo mostra, nas suas contradições, a dificuldade de construir, a partir do conflito, uma consciência crítica em relação às dinâmicas mais amplas da produção corporativa da cidade.

O protagonismo político da comunidade de Saramandaia na eclosão do conflito do HBV pode ser compreendido pela sua própria trajetória de lutas. O conflito permeia a história de Saramandaia, assim como de inúmeras comunidades ameaçadas simplesmente por estarem ali, em áreas cobiçadas pelo capital imobiliário, mas mantidas na invisibilidade. Mudam-se as relações de força quando a sua presença em alguma medida intercepta os planos do capital imobiliário na cidade e o conflito ganha corpo mediante reconfiguração de escala e complexidade. Os dois momentos de conflito trazem configurações e culminâncias de toda uma experiência conflitiva na história de Saramandaia, de conquista e garantia do território conquistado, como processo e produção cultural da sua existência, ou "direitos autoconstruídos" cotidianamente (LIMA, 2019).

Uma história de tensão e conflito representa legado cultural de valores, crenças e repertórios, revelados de forma articulada e contraditória na produção do espaço e na ação política; dimensões de um mesmo processo que podemos entender como exercício do direito à cidade. $\mathrm{O}$ direito à cidade não é dado e não existe como abstração. Em Saramandaia, incorpora os sentidos mobilizados na sua instabilidade e estado de alerta. No conflito analisado, a afirmação da sua presença insólita no Centro revela um dos sentidos do direito à cidade, forte o suficiente para agregar força na interlocução com os agentes trazidos à causa e lograr conquistas.

Os empenhos do urbanismo hegemônico na área não se esgotam no HBV. Novas investidas estão na pauta com um projeto de via pedagiada proposto pela Prefeitura em $2011^{7}$ e, mais recentemente, com a abertura de espaços para o capital imobiliário, a partir da saída da rodoviária, localizada na fronteira do bairro; projetos, inclusive, incorporados ao Plano Diretor aprovado em 2016. Além da rodoviária, o órgão estadual de trânsito, vizinho à rodoviária, será desativado. Os conflitos anunciados alargam as esferas de

${ }^{7} \mathrm{O}$ projeto, objeto de contencioso em curso, atravessa grande parte da cidade e inclui despejos forçados de cerca de 3000 pessoas da comunidade de Saramandaia e mais aproximadamente 6000 pessoas de outras comunidades atingidas (LUGAR COMUM, 2018). Desde o anúncio do projeto as comunidades afetadas se articularam para impedir a execução do projeto. 
interesse e também de luta pelo direito à cidade para a comunidade de Saramandaia. Os novos projetos tensionam a inserção de Saramandaia em dinâmicas na escala metropolitana e, portanto, na relação com dimensões mais amplas e complexas nas lutas pelo direito à cidade. Com o acúmulo de cerca de 40 anos de lutas, a comunidade lida com outros enfrentamentos. Mas, como ecoado nas vozes de tantas pessoas, instituições e entidades mobilizadas a partir da e pela comunidade: Saramandaia Existe! Saramandaia Existe! Saramandaia Resiste $!^{8}$

3.3 Shopping Center E\&C - Elephant and Castle (Londres): regeneração urbana e resistências em um bairro latino americano em Londres

O conflito envolvendo a demolição do pequeno Shopping Center E\&C, estabelecimento voltado para atividades culturais e econômicas para a comunidade formada por grupos étnicos de várias origens, mas predominantemente latinoamericanos de Londres, situado em Elephant and Castle - Southwark, está inserido em contexto mais amplo de delimitação de áreas da cidade pelo London Plan 2002, como "Opportunity Areas". Nessas localidades, busca-se um processo de reestruturação urbana, por meio da convergência entre o poder público local e "parceiros estratégicos", visando à transformálas em territórios atrativos para investimentos, ao alargamento da fronteira do capital e geração de empregos. Para tanto, uma das estratégias de intervenção espacial pode passar pela implementação dos chamados Master Regeneration Plan.

A implantação dos chamados Master Regeneration Plan em Londres não está restrita ao Elephant and Castle e vem sendo criticada por grupos ativistas que lutam pelo direito à cidade. (JUST SPACE, 2015; 35\% CAMPAIGN, 2019, 2019a). Segundo eles, esse modo de fazer cidade traz no seu bojo processos de gentrificação e intensificação da ação especulativa sobre o território, gerando impactos, sobretudo, em relação aos pequenos comerciantes e à habitação de interesse social. ${ }^{9} \mathrm{O}$ Elephant and Castle Master

\footnotetext{
8 Essas são frases de ordem usadas pela comunidade e pela sua rede de articulação na estratégia de visibilização pública do conflito, que incluiu a produção do vídeo Saramandaia Existe! em contraponto à ficção da novela Saramandaia, de Dias Gomes, exibida em 1976, que deu nome à ocupação. No final do vídeo, essas frases são ecoadas na voz do cantor e compositor Gilberto Gil.(LUGAR COMUM; RAS, 2013).

${ }^{9} \mathrm{~A}$ estimativa da organização 35\% Campaign é que a região de Southwark tenha perdido 13 mil council homes (habitação produzida pelo poder público) desde que a estratégia de regeneração foi anunciada em 1999. (35\% CAMPAIGN, 2019a).
} 
Regeneration Plan, chancelado pelo Southwark London Borough Council ${ }^{10}$ teve a sua concepção iniciada em 1999 para ser implementado em 15 anos, envolvendo 1,5 bilhões de libras e em 2007, o consórcio formado pela Lend Lease Group, First Base and Oakmayne foi escolhido para desenvolvê-lo. (ROMÁN-VELÁZQUEZ, 2014).

$\mathrm{Na}$ modelagem de gestão adotada, embora haja uma nítida perda de protagonismo do Estado, assentada no discurso da eficiência e competitividade empresarial, os agentes privados não prescindem do Estado, cabendo-Ihe, dentre outras funções, a criação de um ambiente seguro de negócio e definição de um aparato jurídico que propicie segurança aos investidores. Há também ações que ficam restritas à capacidade soberana do Estado, a exemplo de processos de despejos forçados, frequentemente acionados nos processos de "regeneração urbana". Nesses casos, o poder público local se utiliza do instrumento "compulsory purchase order" que permite a obtenção do imóvel sem o consentimento do morador. Por essa modelagem jurídica, a forma de definição dos critérios das indenizações deixa os moradores em uma situação de vulnerabilidade, não permitindo a aquisição de outro imóvel na mesma região, o que termina por agravar a situação de desmonte progressivo da política de habitação de interesse social britânica, marcada pela diminuição de subsídios e pela demolição do estoque de moradias públicas, e também por uma forte resistência dos movimentos sociais urbanos, a exemplo do 35\% Campaign, The Focus E 15 e outros.

A proposta de demolição do Shopping Center E\&C faz parte das últimas etapas do plano de regeneração de Elephant and Castle. Apenas para melhor contextualizar, a primeira etapa envolveu a demolição, entre 2011 e 2014, de 1.034 unidades habitacionais de interesse social no edifício Heygate Estate. De acordo com a pesquisa desenvolvida pela Best Elephant, organização ativista local, apenas um a cada cinco moradores conseguiu permanecer na área. (BEST ELEPHANT,2019).

O Elephant and Castle Master Regeneration Plan prevê que no lugar do Shopping Center E\&C sejam construídas 979 unidades habitacionais, o campus do London College of Communication, uma torre de 35 andares e o acesso à estação do metrô (BBC, 2019). A estratégia de convencimento inclui a promessa de geração de 1230 empregos em 10 anos (BBC, 2011; 2018) e previsão de espaço com cotas acessíveis para os comerciantes locais. Além das cotas prometidas não contemplarem todos os 
comerciantes, a proposta do novo empreendimento desconsidera as relações étnicosociais construídas naquele espaço e não alcança os arranjos de sublocações informais, situações limiares outrora acolhidas ou acomodadas nos pactos estabelecidos com os proprietários do Shopping. Portanto, os processos e formas culturais presentes e tacitamente acomodados à ordem estabelecida passam a ser acionados para chancelar os despejos dos comerciantes.

Desse modo, a intervenção urbana se vale das fronteiras ambíguas entre o "legal-ilegal" para deslegitimar direitos e o próprio sentido de luta pelo direito à cidade, cuja permanência na centralidade confronta-se com os signos da separação. Há, no mesmo processo, a imposição de uma outra lógica nas relações comerciais, hoje pautadas em relações de clientela, atravessadas por uma rede de solidariedade nutrida por vínculos sociais e culturais. Segundo um dos comerciantes entrevistados, trata-se da transformação de clientes em consumidores, o que não condiz com a dinâmica do Shopping Center E\&C, no qual as relações sociais de vínculos culturais e afetivos importam. Como avalia Roman-Velasquéz (2014), o projeto opera uma transição do informal para redes econômicas transnacionais formais e uma transição na autodefinição: da identidade mono-latina para uma identidade "britânico-latina".

A aproximação com os comerciantes do Shopping Center E\&C e moradores do entorno revelou como essas intervenções vêm colonizando os modos de vida urbana em Elephant and Castle, buscando eliminar toda a forma que foge à racionalidade das propostas contidas no Elephant and Castle Master Regeneration Plan. Esse processo fica evidenciado nos discursos acionados para desqualificar o local pelos agentes públicos e privados e no manejo do aparelho repressivo do Estado. Contraditoriamente, ao tempo em que houve a intensificação da polícia migratória na fiscalização dos documentos de permanência junto aos imigrantes, o Estado restringiu a ação policial na área, levando o local a atrair usuários de drogas e favorecer pequenos furtos. Essa atmosfera de perigo, resultado da ação-omissão do Estado, além de buscar afastar os usuários do Shopping Center E\&C, também contribuiu para construir uma justificativa de intervenção perante a opinião pública, fortemente pautada no discurso de limpeza e segurança. Soma-se a essas ações, a pressão exercida pelo proprietário do shopping, por meio da majoração dos valores dos aluguéis e restrição das ações condominiais voltadas à conservação do espaço. Como evidente reação, parte dos usuários resiste e permanece, demarcando a sua 
participação cotidiana no espaço, através da presença nos espetáculos de salsas, da comercialização de empanadas colombianas e na opção do espanhol como idioma, encontrado nos muros e nos cardápios dos restaurantes latinos.

Restrição e mesmo sonegação de informações também fazem parte da estratégia de estabelecimento de relações assimétricas no desenrolar do conflito. Apesar da exigência de apresentação dos estudos e propostas em audiências públicas, estabelecida em normas, os comerciantes denunciam a utilização de linguagem técnica e a ausência de abertura para alteração nos projetos. Essa conduta levou os atingidos a reivindicarem o direito à cidade, também a partir da chave da participação nos projetos que incidem sobre os territórios que vivenciam, utilizando, para tanto, diversas estratégias e instâncias, dentre elas as vias jurídicas, protestos, elaboração de documentos técnicos, criação de esferas públicas de discussão e fortalecimento de múltiplas formas de sociabilidade. ${ }^{11}$

Como pudemos observar, as contrarreações dos sujeitos envolvidos incluem uma verdadeira guerra de contra-narrativas para fortalecer e legitimar as suas lutas no território e nas redes sociais, dentro e fora do Estado, com base na lei, à margem da lei e até mesmo contra a lei. No campo das políticas públicas urbanas, os sujeitos envolvidos caminham pelas frestas principiológicas do Local Plan, documento referencial da estrutura espacial e de estratégias políticas para a cidade de Londres (PLAN, 2015). Dentre as diretrizes acionadas por eles estão aquelas voltadas para assegurar um percentual de habitação de interesse social e cotas acessíveis para os comerciantes nos novos empreendimentos e a construção de planos de vizinhança que permitam dar visibilidade à dimensão étnico-cultural do Bairro Elephant and Castle, transformando práticas discriminatórias em um fio condutor para estabelecer conexões com outras lutas pelo direito à cidade.

Às vésperas da data marcada para a demolição do Shopping Center E\&C, os atingidos, com o apoio do Up The Elephant campaign, The Public Law Centre and Southwark Law Centre e 35\% Campaign acionaram a High Court, através do instrumento da revisão judicial, buscando anular as decisões das autoridades administrativas que autorizaram a demolição. Ainda sem desfecho, esse conflito mostra assimetrias quanto

\footnotetext{
${ }^{11}$ Registre-se o fato dos antigos moradores do Edifício Heygate Estate terem recorrido ao First-Tier Tribunal General Regularatory Chamber, para garantir o direito à informação. (FIRST- TIER TRIBUNAL, 2014).
} 
aos recursos de poder mobilizados pelas partes envolvidas, mas evidencia a capacidade de articulação dos sujeitos sociais na construção de estratégias políticas, na mobilização do campo jurídico, na busca de legitimidade pública, no enfrentamento do debate técnico como ação política. Coloca em cheque e para a reflexão, as disputas em torno dos planos e o quanto este instrumento pode abrir possibilidades de pensar futuros alternativos, quanto legitimar processos de despossessão pela via do urbanismo corporativo.

A ampliação e interação de escalas nas lutas pelo direito à cidade para manter um território multiétnico dentro de uma centralidade urbana de Londres demonstram que os processos de negação de direitos se comportam também como propulsores de novas ações que conferem sentido à luta pelo direito à cidade e proporcionam a construção de vínculos, através da articulação política com outros coletivos e movimentos sociais na cidade de Londres, conferindo, por sua vez, sentido a um aspecto bastante imbricado no direito à cidade, nos termos propostos por Lefebvre (1991): o direito à obra como atividade participante.

4 Clivagens hierarquizantes: armadilhas da lógica jurídico-urbanística hegemônica

Representações de cidade historicamente acompanharam a produção da cidade, sem necessariamente guardar correspondência com a cidade, dimensão singular de um dado espaço social produzido, nas relações de produção e também de reprodução social (LEFEBVRE, 1991). Embora sejam inúmeras as representações de cidade instrumentais ao projeto neoliberal - cidade produtiva, cidade competitiva, cidade inteligente, cidade sustentável, cidade resiliente e outras - os conflitos analisados instigam a reflexão em torno de, pelo menos, três representações de cidade - cidade real, cidade legal e cidade ideal - as quais curiosamente compareceram na construção da modernidade industrial e persistem na atual fase do capitalismo, como separações para encobrir contradições implícitas e também dificultar o reconhecimento de múltiplas maneiras de produzir cidade e viver na/ a cidade.

As operações dessas representações no espaço social certamente não são as mesmas e nem mesmo se revelam com a mesma força na produção do conhecimento e no planejamento e projetos para as cidades. O projeto da modernização industrial para 
as cidades trazia uma aproximação entre Cidade Ideal e Cidade Legal (das regulações e do zoneamento por exemplo) em oposição frontal e destrutiva à Cidade Real, traduzida na noção de tábula rasa. Uma outra operação parece engendrar e revelar essa tradição, aqui tomada no sentido de uma tradição ativa, como "processo deliberadamente seletivo que oferece uma ratificação histórica e cultural de uma ordem contemporânea" hegemônica (WILLIAMS, 2004, p.119). Hoje, a Cidade Legal ganha corpo para parametrizar e deslegitimar a representação de Cidade Real e aprisionar a representação da Cidade Ideal no "aqui e agora", trazendo incontáveis qualificativos operadores de uma representação de cidade aderente à ordem dominante.

Essa Cidade Ideal contemporânea não é obviamente a representação (ou construção) de uma utopia experimental de cidade, o descortinar de uma imaginação urbanística da sociedade urbana transformada. Historicamente, a Cidade Ideal, mesmo a dos socialistas utópicos, era uma cidade controlada na busca de uma ordem intrínseca fugidia a ser recuperada e associada à racionalidade subjacente. Com isso não pretendemos negar a radicalidade das utopias do passado; ao contrário, mais do que em outros tempos é preciso resgatar perspectivas utópicas no alinhamento entre conhecimento e imaginação, ou, como sugere Vainer (2019), "utopizar" na conjugação plural. Mudar os parâmetros de construção do Ideal e questionar a própria ideia de ordem, da racionalidade burguesa secular é indispensável, assim como é igualmente necessário construir a utopia do presente como força mobilizadora da práxis social.

O sentido da Cidade Ideal como representação do espaço produzido na lógica hegemônica capitalista toma o conteúdo pela forma e encobre os processos e relações de produção do espaço, assim como desiguais processos de reprodução social. (LEFEBVRE, 1991). Na mesma operação comparecem as representações da Cidade Legal como baliza para o enquadramento do futuro no modelo prescrito para uma Cidade Real, supostamente deformada ou disforme (Cidade Informal) frente ao parâmetro da legalidade estabelecida como representação do real-ideal. A legislação urbanística opera como uma espécie de molde para a Cidade Ideal, consagrando como lei "as morfologias dos produtos imobiliários ofertados na cidade e reforça a gestalt discriminatória da cidade". (ROLNIK, 2015, p. 186) como operação da Cidade Legal. Ainda segundo Rolnik (2015, p. 187), "Trata-se também de uma poderosa maquinaria de discriminação ético- 
cultural, que define como "proibidas" formas de morar inscritas em certas práticas socioculturais."

Confrontar as representações de cidade nas suas clivagens obstrutivas do conhecimento dos processos e relações contraditórias da produção do espaço e da práxis potencialmente emancipatória, quer seja no campo do direito ou do planejamento urbano é tarefa relevante do projeto político do direito à cidade. O legal e o ilegal entram em cena ditando o formal (e o informal), ou seja, as formas e formações consideradas culturalmente legítimas e ilegítimas, no empenho de captura do ideal como utopia do pensar e construir futuros alternativos.

Esses enquadramentos operam dualidades pautadas em uma visão que propõe um casamento indissociável entre a lei e o direito, sustentado no positivismo dogmático e na aposta do Estado como o único produtor da norma jurídica. Por essa visão, oculta-se uma multiplicidade de formas jurídicas existentes no seio das relações sociais que não foram reconhecidas pela ordem jurídica estatal ou subjugam direitos inscritos no ordenamento jurídico não lastreados na forma-propriedade (direitos culturais imateriais, formas coletivas de apropriação do território) ou que têm como titular grupos sociais específicos (mulheres, sem teto, moradores dos territórios populares, povos e comunidades tradicionais, negros e negras, pessoas com deficiência, migrantes, população LGBTIQ+, população em situação de rua e outros).

Essa contraposição entre legal e ilegal se comporta como uma dualidade forjada na ordem dominante que na prática impõe à ordem jurídica estatal a sua apresentação como referencial para arbitragem dos conflitos urbanos. Essa centralidade exercida pelo Direito Estatal tem como corolário uma relação assimétrica de juridicidade que termina por promover hierarquizações, ocultamentos e estigmatizações. Nessa trama, são nutridas polarizações que enquadram como ilegais, informais, desordenadas, irregulares, clandestinas, as práticas sociais de acesso à cidade da classe trabalhadora e tenta restringir o seu reconhecimento à forma propriedade-individual. No âmbito do direito processual, as narrativas cedem lugar à "caracterização do "invasor", figura que se constrói desde "fora do Direito" e que, uma vez reconhecida, autoriza a intervenção jurisdicional para a extinção do conflito por meio dos despejos coletivos forçados." (MILANO, 2017, p. 17). 
Nos conflitos analisados foi possível perceber que, ainda que os territórios não estivessem enquadrados em situações frontalmente contra-legem, encontravam-se caracterizados por camadas superpostas e mutuamente imbricadas de relações jurídicas, sendo que parte delas fogem ao paradigma dominante do direito, colecionando outras formas jurídicas que passam pela apropriação coletiva do território (Horto Bela Vista), sobreposição entre relações consideradas informais e formais (Shopping Center E\&C) e utilização de espaços públicos, respaldados em práticas costumeiras (Centro de Abastecimento).

Essa situação de vulnerabilidade, na qual a intervenção do Estado combina gestão e eliminação, nos momentos da eclosão dos conflitos faz com que os moradores desses territórios já entrem na disputa em uma situação de fragilidade, contribuindo com a construção, segundo Rolnik (2015) de uma "transitoriedade permanente", que marca o caráter de "reserva" da terra. (ROLNIK, 2015, p.194). Por outro lado, dialeticamente essa situação não é absoluta e leva os sujeitos coletivos de direito, através das suas práticas experiências, solidariedade e lutas - a inverter e subverter a ordem disciplinar, gerando uma ordenação sociopolítica, guiada pelo ideário do direito à cidade.

Nessa perspectiva, ainda que se parta da compreensão do Direito enquanto instrumento histórico de sustentação das condições de hegemonia capitalista, importa percebê-lo como um campo de luta aberto e indefinido, pelo qual é possível, em alguma medida, construções contra-hegemônicas, aproveitando das suas próprias contradições. Para tanto, adotar uma visão relacional e mutante do direito é fundamental, como nos propõe Roberto Lyra Filho, como contribuição para esse enfrentamento. Segundo o autor, Direito é processo, dentro do processo histórico; não uma coisa feita, perfeita e acabada; é aquele vir-a-ser que se enriquece nos movimentos de libertação das classes e grupos ascendentes e que definha nas explorações e opressões que o contradizem, mas de cujas próprias contradições brotarão as novas conquistas. (LYRA FILHO, 1984).

Assim como o Direito, o planejamento urbano se insere no jogo de forças podendo ser tensionado para legitimar e reproduzir uma dada ordem urbanística hegemônica com o seu "modelo" de cidade e ao mesmo tempo como instrumento de luta social. Assim, se de um lado o "modelo" tenta se impor como representação de uma ordem hegemônica, com seus impulsos de diversas ordens, escalas e temporalidades, o "norte" é permanentemente disputado pelas forças sociais em ação (RIBEIRO, 2011). 0 
plano, o projeto e a lei, embora sejam instrumentos permanentemente acionados na conformação do "modelo", a captura do "norte" não se coloca a priori ou é passiva. Com seu horizonte gerador de alternativas de futuro o plano permite explorar a dialética "possível-impossível" de uma "política do espaço" quando o espaço, religado a uma prática social (LEFEBVRE, 1991), cria a possibilidade do emergente (WILLIAMS, 2004). Isso pressupõe a subversão ao modelo, forjado como moldura do pensar e agir coletivo, como um envoltório restritivo da imaginação e ação.

Contra o modelo e as representações de cidade inscritas comparece a cidade como obra aberta, dimensão criativa e insubordinada dos agentes que a produzem e dela se apropriam no processo conflitivo e contraditório das relações próprias dessa produção, não se subordina a prescrições normativas e às representações de uma dada ordem hegemônica. O caráter singular da cidade e do direito à cidade (MARCUSE, 2010) pressupõe reconhecer a cidade como campo de construção de práticas e de repertórios da própria ação e experiência dos agentes sociais. Com sua história e relações de poder engendradas em diferentes temporalidades nos processos sociais, culturais e políticos (WILLIAMS, 2004), a cidade se abre às tensões das disputas de hegemonia na sua condição de obra e assim pode revelar saberes e fazeres como potenciais de transformação ou ser contida na reprodução de formas históricas de desigualdade, opressão e segregação.

$\mathrm{O}$ direito à cidade tem sido a força agregadora das lutas urbanas no Brasil e em outros países, sobretudo da América Latina, reivindicado em distintas acepções e práticas de resistência (VIVEIROS, 2018). Em Lefebvre (1991), o direito à cidade corresponde ao resgate da cidade como obra, valor de uso que se afirma na produção e apropriação da cidade e na concepção de uma utopia urbana que certamente dispensa representações pré-concebidas de cidade descoladas da práxis dos seus habitantes.

\section{Considerações finais: sentidos das lutas pelo direito à cidade}

Nas três situações discutidas, o conflito emergiu no alargamento das fronteiras do capital corporativo, sendo atravessado por questões territoriais, nas dimensões material e simbólica, no sentido colocado por Haesbaert (2004), acionando inclusive dimensões raciais e de gênero. Motivado pela oportunidade de captura da cidade enquanto negócio, 
opera-se uma sinergia entre o urbanismo corporativo, capital financeiro e instâncias estatais que acionam instrumentos jurídicos para supervalorização da propriedade privada em detrimento dos usos comum e popular. Aciona-se a dualidade legal-ilegal para moldar uma lógica de produzir cidade, forjada por meio de silenciamentos, desconstituição das esferas públicas, gentrificação e despejos forçados. Como contraponto, os sujeitos coletivos - imigrantes latinos e africanos, artesãos, comunidade LGBTIQ+, moradores de favelas, líderes de religiões de matriz africana - promovem articulações interescalares e protagonizam a sua história para afirmar o direito à cidade.

Os conflitos analisados apontam para essa perspectiva de ampliação de repertórios no sentido do descentramento em relação ao direito positivo e ao planejamento tecnicista a partir de uma aposta contra-hegemônica e uma visão plural em relação ao Direito. No jogo de forças, recursos técnicos e jurídicos foram mobilizados, assim como repertórios legitimadores nas disputas pelo direito à cidade foram ampliados, alimentando, ainda com largo distanciamento, o horizonte utópico proposto por Lefebvre (1991), sobretudo diante das distopias do atual contexto. Observados de perto, os conflitos abarcam agendas mais imediatas sem alcançar esferas mais amplas de confronto com as investidas do capital, seus complexos arranjos produtores de segregação, fragmentação e despossessão. Essa afirmação de modo algum retira a densidade, força e complexidade das ações políticas desenvolvidas pelos sujeitos coletivos de direitos contra o urbanismo corporativo, mas aponta o quanto este é capaz de acomodar situações oposicionais e suas reivindicações, inclusive por meio do acionamento do campo jurídico.

O conflito como momento produtor de conhecimento e construtor de consciência crítica; de formação de identidades coletivas, de produção de juridicidades alternativas ficou evidenciado na observação e reflexão sobre os processos nas situações analisadas. Ainda que sutis, sinais de processos emergentes (WILLIAMS, 2004) se apresentam no esforço de construção de alianças de diferentes perfis e escalas pelos sujeitos coletivos de direitos em situação de conflito, na força subjacente aos processos culturais capazes de evidenciar o amálgama entre a cultura e o político e na afirmação do direito à centralidade como dimensão estratégica na conquista do direito à cidade.

Os sentidos conferidos ao direito à cidade pelos diversos coletivos, nos casos estudados, envolvem a luta pela centralidade, visibilidade, participação, construção de espaço público/comum, preservação das expressões e práticas culturais, e apesar das 
pressões e limites definidos pelas relações de força nos respectivos contextos, apontam que os acúmulos vivenciados podem seguir na direção de um direito: direito à cidade, isto é, à vida urbana, condição de um humanismo e de uma democracia renovados. (LEFEVBRE, 1991). Sinais de ampliação de escalas podem ensejar conexões mais amplas e complexas e, nessa complexidade, instigar a consciência crítica para atribuição de novos sentidos à luta pelo direito à cidade.

Referências bibliográficas

BBC NEWS LONDON. Elephant and Castle shopping centre to be redeveloped. 17 May 2011. Available:< http://www.bbc.co.uk/news/uk-england-london-13427253>. Access: 18 maio 2018.

BBC NEWS LONDON Elephant and Castle shopping centre demolition gets final approval. https://www.bbc.com/news/uk-england-Iondon-46524339. Acesso em 11 dez de 2018.

BETTER ELEPHANT. Regeneration Branded "Miserable Failure" at CPO Publico Inquiry. Disponível em http://betterelephant.github.io/blog/2013/07/18/regeneration-brandedmiserable-failure-at-cpo-public-inquiry/ Acesso em out. 2019.

BURAWOY, Michael. The extended case method. Sociological Theory. Volume: 16, p. 433. Disponível em https://journals.sagepub.com/doi/10.1111/0735-2751.00040. Acesso em 10 jun. 2019.

CAMPAIGN 35\%. The Southwark Clearances. Disponível em http://35percent.org/thesouthwark-clearances/\#city-villages. Acesso em out de 2019.

CAMPAIGN 35\%. High Court hearing looms for Elephant shopping center. Disponível em http://35percent.org/2019-10-17-day-of-decision-for-elephant-shopping-centre/Acesso em out de 2019a.

DAGNINO. Evelina ¿Sociedade civil, participação e cidadania: de que estamos falando? Caracas: FACES, Universidad Central de Venezuela, 2004.

DAS, Veena and POOLE, Deborah. State and Its margins: comparative ethnographies In: DAS, Veena and POOLE, Deborah. Anthropology in the margins of the State.School of American Research Press. Santa Fé, 2004.

FIRST- TIER TRIBUNAL. General Regulatory Chamber. Information Rights. Appellant: London Borough of Southwark. Respondent: The Information Commissioner, Lend Lease (Elephant and Castle) Limited e Adrian Glasspool. Judge: NJ Warren, 9 May 2014 
GRAMSCI, Antonio. Cadernos do Cárcere. 5a ed. Rio de Janeiro: Civilização Brasileira, 2012. Volume 3.

GOMES, Itania. Raymond Williams e a hipótese cultural da estrutura de sentimento. In: GOMES, Itania e JANOTTI JR., Jeder. Comunicação e Estudos Culturais, Salvador, Edufba, 2011.

GOMES, Rafaela Maria da Conceição Silveira. Um Shopping no Meio da Feira: a descaracterização do Centro de Abastecimento de Feira de Santana e suas implicações jurídicas no campo da cultura. Monografia em Direito, Universidade Federal da Bahia, Salvador, 2018.

HAESBAERT, Rogério. Dos Múltiplos Territórios à Multiterritorialidade. Porto Alegre, 2004. Disponível em:\&lt;http://www.ufrgs.br/petgea/Artigo/rh.pdf\&gt;. Acesso em: 20 Nov. 2019.

HOLSTON, James. Legalizando o ilegal: propriedade e usurpação no Brasil. Revista Brasileira de Ciências Sociais, v. 8, n. 21, p. 68-89, fev. 1993.

JUST SPACE. London for all. A handbook for community and small businesse groups fighting to retain workspace for London's diverse economies.Just Space. Londres, 2015.

LEFEBVRE, Henri. O direito à cidade. Trad. de Rubens Eduardo Frias. São Paulo: Centauro, 1991.

Revolução Urbana. Belo Horizonte: Editora UFMG,1999.

LIMA, Adriana Nogueira Vieira. Do direito autoconstruído ao direito à cidade: porosidades, conflitos e Insurgências em Saramandaia. Salvador: EDUFBA, 2019.

LUGAR COMUM; RAS - Rede de Associações de Saramandaia. Vídeo "Saramandaia Existe", 4 min. Produção: CARVALHO, Marcos Oliveira e MERCÊS, Deise Lima das, publicado em 20 jun. 2013. Salvador, FAUFBA, 2013. Disponível em http://youtu.be/d1EqgxmlFPk. Acesso em 12 dez. 2018.

LUGAR COMUM. Grupo de Pesquisa Lugar Comum. Universidade Federal da Bahia. Plano de Bairro de Saramandaia, 2018.

LYRA FILHO, Roberto. Para um direito sem dogmas. Porto Alegre: Fabris Editor, 1980.

Porque estudar direito hoje? Brasília: Edições Nair, 1984.

MARCUSE, Peter. In: SUGRANYES, Ana; MATHIVET, Charlotte (orgs.) Ciudades para tod@s: Por el derecho a la ciudad, propuestas y experiências. Habitat International Coalition (HIC). Santiago do Chile, 2010. pp.91-104.

MILANO, Giovanna Bonilha. Conflitos urbanos e Poder Judiciário. Curitiba: Ithala, 2017. 
MOUFFE, Chantal. La Politica y lo político. In: En Torno a lo Político. Buenos Aires: Fondo de Cultura Económica, 2007.

NOGUEIRA, Marco A. As três políticas. In: Em defesa da política. São Paulo: Editora SENAC, 2001.

PLAN LOCAL 2015. Department of the Built Environment. Disponível em https://www.cityoflondon.gov.uk/services/environment-and-

planning/planning/planning-policy/local-plan/Documents/local-plan-2015.pdf. Acesso em 20 set. 2019.

PACHECO, Larissa Penelu Bitencourt. Trabalho e costume de feirantes de alimentos: pequenos comerciantes e regulamentações do mercado em Feira de Santana (1960/1990). Dissertação de mestrado em História. Feira de Santana, UEFS, 2009.

PLANARQ. Planejamento Ambiental e Arquitetura. Estudo de Impacto Urbano Ambiental (EIUA) do Empreendimento Horto Bela Vista, localizado em Salvador/BA. Tomo I, vol. 01 e vol. 02, 2010.

PREFEITURA DE FEIRA DE SANTANA. Edital de Licitação no 108/2015, na modalidade Concorrência Pública no 014/2015.

RIBEIRO, Ana Clara T. A Força do Passado: Nem tudo que é Sólido Desmancha no Ar. Disponível em: http://labcs.ufsc.br/files/2011/12/01.-RIBEIRO-A.C.T.-A-for\%C3\%A7a-dopassado.pdf. Acesso em: 20 jun. 2018.

ROLNIK, Raquel. Guerra dos lugares: a colonização da terra e da moradia na era das finanças. São Paulo: Boitempo, 2015.

ROMÁN-VELÁZQUEZ. Claiming a place in the Global City: urban regeneration and latinamerican spaces in London. Revista Eptic Online. Vol. 16 n. 1 p. 84-104, jan-abr. 2014.

SOUSA SANTOS, Boaventura de. A crítica da razão indolente: contra o desperdício da experiência. São Paulo: Cortez, 2000.

SOUSA JÚNIOR, José Geraldo. O direito como liberdade, Porto Alegre, SAFE, 2011.

TELES, Alessandra Oliveira. O comércio informal em Feira de Santana (BA) permanências e mudanças. Tese de Doutorado em Geografia. Sergipe, UFS, 2017.

THOMPSON, Edward Palmer. A Miséria da Teoria ou um Planetário de Erros: uma crítica do pensamento de Althusser. Rio de Janeiro: Zahar, 1981.

Costume, lei e direito comum. In: THOMPSON, E. P. Costumes em comum. Estudos sobre a cultura popular tradicional. Revisão técnica Antonio Negro, Cristina Meneguello, Paulo Fontes. São Paulo: Companhia das Letras, 1998 
VAINER, Carlos. Palestra proferida no Seminário Nacional Prevenção e Mediação de Conflitos Fundiários Urbanos promovido pelo Programa Nacional de Capacitação das Cidades/ Conselho Nacional das Cidades/ Ministério das Cidades e Organizado pelo GT Conflitos Fundiários Urbanos na Mesa intitulada Visão do Movimento Social, da Universidade e do Governo Federal sobre a Prevenção e Mediação dos Conflitos Fundiários Urbanos, 2007.

VIVEIROS, Liana. Práxis de Política Urbana no Brasil: Movimentos e Articulações Nacionais e Internacionais na Construção do Direito à Cidade. 407 f., 2018. Tese (Doutorado). Programa de Pós-Graduação em Arquitetura e Urbanismo, Universidade Federal da Bahia, Salvador, 2018.

WILLIAMS, Raymond. Marxismo e Literatura. Tradução Waltensir Dutra. Rio de Janeiro: Jorge Zahar, 2004. (1a edição de 1971).

Cultura é algo Comum. In: WILLIAMS, Raymond. Recursos da Esperança: Cultura, Democracia, Socialismo. Trad. Nair Fonseca e João Alexandre Peschanski, 1a Ed. São Paulo: Unesp, 2015.

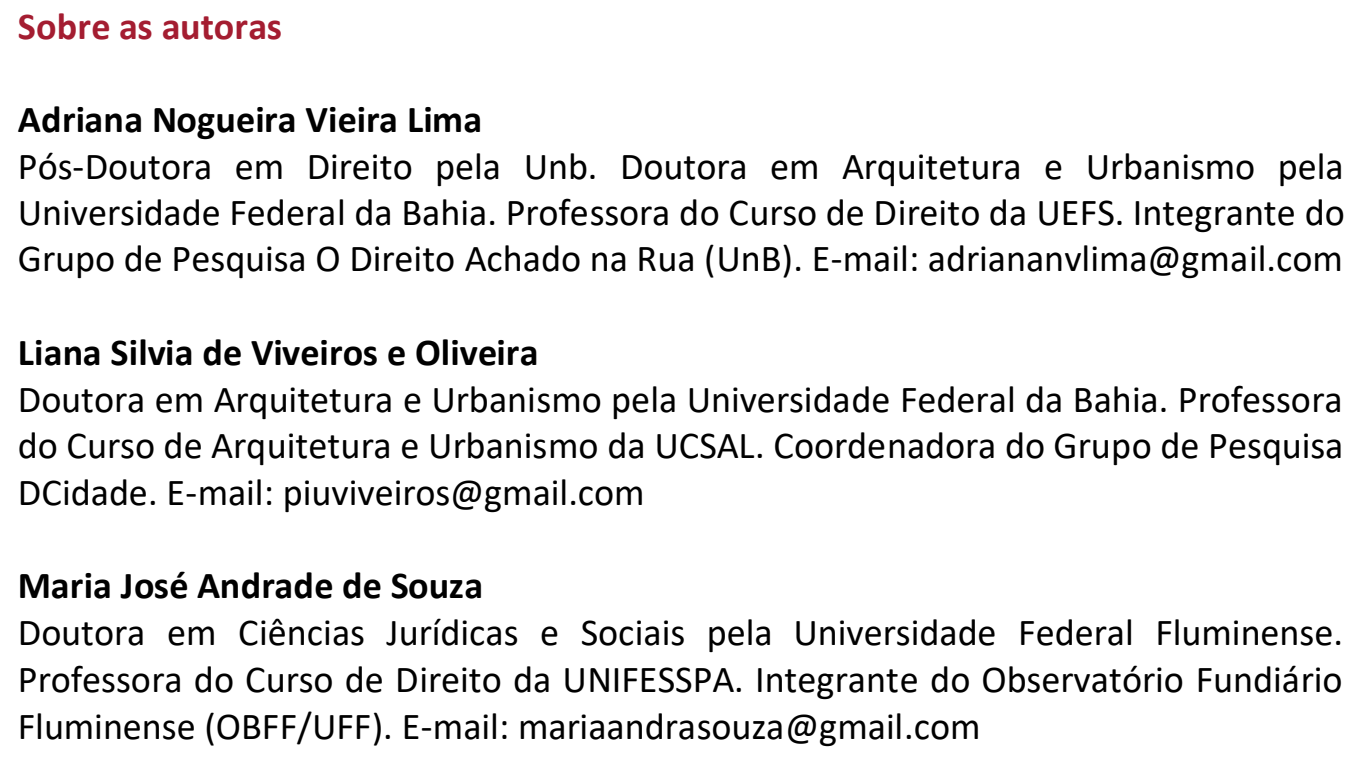

\section{Liana Silvia de Viveiros e Oliveira}

Doutora em Arquitetura e Urbanismo pela Universidade Federal da Bahia. Professora do Curso de Arquitetura e Urbanismo da UCSAL. Coordenadora do Grupo de Pesquisa DCidade. E-mail: piuviveiros@gmail.com

\section{Maria José Andrade de Souza}

Doutora em Ciências Jurídicas e Sociais pela Universidade Federal Fluminense. Professora do Curso de Direito da UNIFESSPA. Integrante do Observatório Fundiário Fluminense (OBFF/UFF). E-mail: mariaandrasouza@gmail.com

As autoras contribuíram igualmente para a redação do artigo. 